\title{
Surto alimentar por Salmonella Enteritidis no Noroeste do Estado de São Paulo, Brasil
}

\author{
Outbreak of Salmonella Enteritidis in northwest of S. Paulo State, Brazil
}

\author{
M. Kaku, J.T.M. Peresi, A.T. Tavechio, S.A. Fernandes, A.B. Batista, I.A.Z. \\ Castanheira, G.M.P. Garcia, K.Irino, D.S. Gelli \\ Instituto Adolfo Lutz, São José do Rio Preto - Brasil (M.K., J.T.M.P., A.B.B., I.A.Z.C.); \\ Instituto Adolfo Lutz - Central - São Paulo - Brasil (A.T.T., S.A.F., K. I., D.S.G.); \\ Escritório Regional de Saúde de Jales - ERSA 40 - Brasil (J.M.P.G.)
}

\begin{abstract}
Em 1993 ocorrej um surto alimentar em escola, com 211 afetados. Os dados epidemiológicos levantados por entrevista de amostragem de afetados e não afetados mostraram que os sintomas predominantes foram dlarréia, febre $(77,7 \%)$, dor abdominal $(67,7 \%)$, vômito $(65,6 \%)$, calafrios $(54,5 \%)$ e cefaléia $(44,5 \%)$. A mediana de incubaçāo foi de 17 horas, com limites entre 3 e 29 horas. A duraçảo da doença foi de 3 a 4 dias. $O$ alimento consumido foi um tipo de patê, mistura de molho de maionese preparada com ovos crus com batata cozida, passado em pão. A análise de material biológico (3 coproculturas) e de restos de alimentos revelou a presença do mesmo microrganismo, a Salmonella Enteritidis. No caso dos alimentos, o número encontrado desta bactéria por gramo de produto era compativel com a quantidade de células necessárla para desencadear a doença (1040 105\%). 0 antibiograma de todas as cepas isoladas reveiou o mesmo padrāo de sensibilidade. As falhas no preparo do alimento relacionadas com - levantamento indlcam a possibilidade de contaminação endógena dos ovos; contaminaçāo cruzada - o surto afetou trés períodos escolares, sendo que para cada um o alimento foi preparado em separado - a as condiç̋es de manutençāo do alimento após preparo $\theta$ até o consumo. A observaçăo por uma semana seguida das 3 merendeiras envolvidas, através de coprocultura, não indicaram que as mesmas fossem portadoras assintomáticas desta bactéria ou que tivessern sido envolvidas no surto em questão.
\end{abstract}

Intoxicação alimentar por Salmonella. epidemiologia. Surtos de doenças. Salmonella, isolamento \& purificação.

\section{Introdução}

Tem sido registrado aumento considerável de relatos de surtos alimentares por Salmonella Enteritidis (SE) nos últimos 15 anos, em todo o mundo.

Nos Estados Unidos, os relatos iniciais referemse a New England, seguida de outros Estados, como Illinois, Kentucky, Tennessee, Minnesota, Maryland, Pensilvania e Califomia 4, 5, 6, 10, 14, 24. No Reino Unido, o número de surtos por SE tem aumentado, sendo 392 e 12.522 o relato do isolamento dessa bactéria em 1981 e 1988, respectivamente. Em vários locais dessa região têm sido descritos surtos, como os relatos de Cowden 1,7.22.
Outros países da Europa, como Holanda ${ }^{22}$, Suiça ${ }^{21}$, Alemanha12 e Itália $^{3}$ têm registrado surtos de salmonelose, sendo a SE o sorotipo mais freqüente. No período de 1986-88, foram relatados 39 episódios na Argentina9. A SE foi responsável por surto também no Brasil, conforme descriçāo no Paraná, em 198115 .

Nos últimos 4 anos, esse sorotipo tem sido isolado com freqüência em nosso meio, tanto de materiais de origem humana como de alimentos. Em 1993, já figurava entre os 10 sorotipos de Salmonella mais comuns*.

Os alimentos mais envolvidos na veiculação da SE são à base de aves e ovos: produtos preparados com ovos e/ou gemas cruas e cames de aves mal 
cozidas ou contaminadas cruzadamente após coç̧ão6.18,20,22,

No presente trabalho é descrito surto alimentar e sua caracterização epidemiológica e laboratorial ocorrido em Pontalinda, Noroeste de São Paulo.

\section{Material e Método}

Coleta de dados - Em 30 de julho de 1993, em escola estadual de primeiro grau, Pontalinda, São Paulo. ocorreu um surto alimentar. A escola tinha 782 alunos matriculados e 68 funcionários, incluindo os professores, totalizando 850 pessoas. Destas, 772 pessoas consumiram patê (mistura de molho de maionese e batata cozida), preparado na escola, e pão, adquirido em padaria local. No dia seguinte, várias pessoas com sintomas clínicos procuraram atendimento médico no Centro de Saúde. A Equipe Técnica da Vigilância Sanitária do Escritório Regional de Saúde 40 de Jales, foi deslocada para Pontalinda, para a realizaçāo da investigação. Foi possível aplicar 320 questionários para análise de sintomas prevalentes, período de incubação, faixa etária e sexo dos entrevistados, número de hospitalizados, duração da doença, histórico de preparação do alimento e outros.

Coleta de amostras - Foram coletadas amostras de pão, de patê e de ovos da cozinha da escola. As amostras foram acondicionadas e transportadas adequadamente e encarninhadas de imediato ao laboratório. Foram realizadas coproculturas de um paciente hospitalizado em Pontalinda e de dois internados na Santa Casa de Jales, que ainda nāo haviam recebido medicação antibiótica. Foram realizadas 15 coproculturas sucessivas, coletadas por "swab" retal das 3 merendeiras, por um periodo de 7 dias. Os "swabs" foram transportados em meio de Cary-Blair.

Análise das amostras - As análises, com exceção de duas coproculturas realizadas na Santa Casa de Jales, foram processadas no Laboratório do Instituto Adolfo Lutz (IAL) de São José do Rio Preto. As amostras de patê e de pão foram analisadas para verificar presença e quantificar a Salmonella, por homogeneização de $25 \mathrm{~g}$ em $225 \mathrm{ml}$ de água peptonada tamponada (APT), e de diluições seriadas até $10^{-7}$ também em APT, incubados por $18-24 \mathrm{~h} \mathrm{a} 35^{\circ} \mathrm{C}$. $O s$ meios de enriquecimento seletivo usados foram caldo selenito, caldo tetrationato e caldo RappaportVassiliadis, incubados a $42^{\circ} \mathrm{C}$ por 24 e $48 \mathrm{~h}$. Após cada período de incubação, o material de cada caldo seletivo foi semeado em meios seletivos-diferenciais de agar Salmonella-Shigella e agar Verde Brilhante, incubados por 18-24h. As colônias suspeitas foram isoladas em meio $\mathrm{IAL}^{16}$. As colônias características foram confirmadas por sorologia polivante somática (O) e flagelar (H). Foram analisados 12 ovos para presença/ausência de salmonelas: 3 inteiros, 6 claras e gemas e 3 somente gemas.

As amostras de material fecal foram processadas de acordo com a metodologia descrita por Pessôa e col. ${ }^{17}$.

Identificação das cepas - As cepas com caracterização e sorologia polivalente correspondente, foram enviadas ao IAL Central, Seção de Bacteriologia Médica. A confimnação bioquímica foi realizada no meio presuntivo IAL $^{16}$, com complementação conforme descrito por Edward $\mathrm{e}$ Ewing ${ }^{8}$. A caracterização de espécie e subespécie foram determinadas pelo esquema de sorotipagem para Salmonella segundo Kauffmann-White ${ }^{18}$.

Sensibilidade aos agentes antimicrobianos Os testes foram realizados segundo metodologia de Kirby e Bauer ${ }^{2}$, utilizando discos CECON frente a carbenicilina, gentamicina, canamicina, cloranfenicol, fosfomicina, amicacina, tetraciclina, sulfazotrim, cefazolina, imipenem, cefaloxitina, ampicilina, cefalotina, tobramicina, ofloxacina, ciprofloxacina e ceftazidime.

\section{Resultados}

Dados epidemiológicos - Foi considerado como afetado o que apresentou coprocultura positiva e o que apresentou pelo menos dois sintomas compatíveis com os de salmonelose, no período não superior a $72 \mathrm{~h}$ após o consumo da refeição. Através deste critério, 211 foram considerados afetados, os quais freqüentavam a escola tanto no período da manhã, como da tarde e da noite ( 3 turnos).

Da enquete, houve a devolução de 211 questionários respondidos $(65,9 \%)$. Pela análise dos mesmos, calculou-se a mediana do período de incubação de 17 horas, com limites que variaram entre 3 e 29 horas; sintomas prevalentes: diarréia e febre $(77,7 \%)$, cólicas/dores abdominais $(67,7 \%)$, vômito $(65,8 \%)$, calafrios $(54,5 \%)$ e cefaléia $(44,5 \%)$. Todos os afetados que responderam a enquete haviam consumido o alimento, sendo $54,0 \%$ do sexo masculino e $46,0 \%$ do feminino. A faixa etária dos afetados foi de 7 a 33 anos, sendo que a de 6-10 anos apresentou maior número de casos, assim como os alunos do período da manhã. Os demais dados levantados referem-se ao período de duração da doença - de 3 a 4 dias; gravidade dos sintomas: maior nos alunos do período da manhã, 
com maior número de internações hospitalares; evolução benigna da doença, com recuperaçâo dos afetados. Foram hospitalizados 82 doentes ( $38,9 \%$ ), sendo 21 adultos e 61 crianças; os demais casos foram tratados ambulatorialmente. A medicação foi por antibioticoterapia e hidratação oral ou endovenosa, segundo à necessidade.

O alimento incriminado foi preparado separadamente para cada turno escolar: os ovos, sem lavagem prévia, foram quebrados e a clara e gema batidos no liquidificador com bleo de soja e temperos, para a confecção do molho de maionese. Essa maionese foi misturada em "mixer" a urma pasta de batata ou seja, cozida em água e amassada. O patê assim obtido foi passado em pão comum, adquirido de padaria local. $\mathrm{O}$ alimento foi mantido à temperatura ambiente por cerca de duas horas até o consumo. A higienização dos equipamentos usados foi feita por lavagem comum.

Resultados laboratoriais - Foram isoladas SE de 5 amostras ( 3 de fezes e 2 de alimentos). As amostras de patê e de pão, analisadas em separado, apresentaram positividade para $\mathrm{SE}$ até as diluições de $10^{-5}$ e $10^{-4}$, respectivamente. As amostras de ovos foram negativas para Salmonella. As 5 cepas isoladas foram sensíveis a todos os agentes antimicrobianos testados.

\section{Discussāo e Conclusões}

A salmonelose figura como uma das mais importantes enfermidades transmitidas por alimentos, segundo a Organizaçăo Mundial da Saúde, seja pelo número de pessoas afetadas, complicações e seqüelas da doença, quantidade e volume de produtos alimentícios contaminados, seja pela perda econômica com tratamento médico/hospitalar ou reprocessamento/destruição de alimentos ${ }^{25}$. Conforme já assinalado, a SE tem apresentado larga distribuição epidemiológica e número crescente de surtos: so em 1991, foram relatados 66 surtos por esse sorotipo, nos Estados Unidos 5 .

No Brasil, os surtos de enfermidades pelo consumo de alimentos não são analisados sistematicamente; porém, o relato de surto por salmonelose ocorrido em Araraquara, S. Paulo, por Salmonella bredeney, afetando 561 funcionários de uma empresa com 42 hospitalizaçỏes $(7,5 \%)^{13}$, é significativo da extensāo do problema. No surto ocorrido no Paraná, em $1981^{15}$, dos 181 afetados em surto por SE, 40 foram hospitalizados $(22,1 \%)$.

No presente trabalho, verificou-se que o número de hospitalizações foi relativamente alta
$(38,9 \%)$, seja por ter envolvido crianças (faixa etária menor, mais sensível à doença), seja por características de patogenicidade da cepa envolvida, possibilidade corroborada por Mota e col. ${ }^{15}$

A grande maioria dos surtos por SE relatados fazem referência a veiculação por produtos e subprodutos à base de ovos ${ }^{19}$. Entretanto, o ovo contaminado nāo contém mais do que 10 desses microrganismos viáveis ${ }^{11}$. A positividade para a SE menor que $1 \% 6,23$, a partir de unidades de ovos analisadas. Assim, o isolamento de Salmonella de um único ovo ou de alguns ovos é raro, sendo necessária a análise de "pool" ou grande mistura para esse isolamento 20 . A Salmonella pode estar na gema, como consequiência da sua introdução ainda no oviduto da ave e na casca, como conseqüência do contacto com fezes na passagem pela cloaca da ave.

No caso de ovos com manchas, pequenas trincas e rachaduras na casca, a contaminação/recontaminação é mais provável ${ }^{11,19}$. No presente trabalho, considera-se baixo o número de ovos analisados. Porém, não é descartada a possibilidade da introdução da SE por esse produto.

A contaminação cruzada, via utensílios ou equipamentos é uma possibilidade sempre presente no preparo final de alimentos. No presente levantamento, considera-se que a introduçāo da SE pode ter acontecido pelos ovos e sua permanência e disseminação foi favorecida por lavagem e desinfecção insuficientes dos equipamentos. Note-se que as coproculturas das merendeiras foram sistematicamente negativas para Salmonella, o que indica que as mesmas não eram portadoras e não foram envolvidas no surto.

As enfermidades alimentares por consumo de ovos crus, particularmente as causadas por SE, revela-se atualmente como um problema de saúde pública, conforme os relatos da literatura ${ }^{23}$ e do presente trabalho.

Os cuidados com a saúde das aves, em especial as poedeiras; os processos de seleção, lavagem, acondicionamento e outros podem prejudicar a qualidade dos ovos. A pasteurização de gemas e misturas de clara e gema devem ser incentivados, por ser uma medida preventiva considerada adequada.

Conclui-se que os processos rotineiros durante a manipulação e preparo de alimentos devem ser objeto constante de cuidado e atençăo, assim como a necessidade de observaçōes epidemiológicas e de programas específicos para a prevenção/correção das falhas que favorecem/determinam os surtos alimentares. 


\section{Referéncia Bibllográficas}

1. BARNES, G.H. \& EDWARDS, A.T. An investigation into a outbreak of Salmonella entertidis phagetype 4 infection and the consumption of custard slices and trifles. Epidemiol. Infect., 109: 397-403, 1992.

2. BALER, A.W.; KIRBY, W.M.M.; SHERRIS, J.C.; TURK, M. Antibiotic susceptibility testing by a standardized single disk method. Am. J. Clin. Patbol, 45: 493-6, 1966.

3. BINKIN, N.; SCUDERI, G; NOVACO, F; GIOVANARDI, G.L.; PAGANELLI, G.; FERRARI, G.; CAPPELLI, O.; RAVAGLIA, L.; ZILIOLI, F.; AMADEI, V.; MAGLIANI, W.; VIANI, I.; RICCO, D.; BORRINI, B.; MAGRI, M; ALESSANDRINI, A.; BURSI, G.; BARRIGAZI, G.; FANTASIA, M.; FILITECI, E.; SALMASO, S. Egg related Salmonella enteritidis, Italy, 1991. Epidemiol. Infect., 110:227-37, 1993.

4. CENTERS FOR DISEASE CONTROL. Outbreak of Salmonella enteritidis gastroenteritis California, 1993. MMWR, 42(41): 793-7, 1993.

5. CENTERS FOR DISEASE CONTROL. Outbreak of Salmonella enteritidis infection associated with consumption of raw shell eggs, 1991. MMWR, 41(21):369-72, 1992.

6. CENTERS FOR DISEASE CONTROL. Update: Salmonella enteritidis infections and shell eggs - United States, 1990. MMWR, 39(50): 902-12, 1990.

7. COWDEN, J.M; CHISHOLM, D.; OMAHONY, M.; LYNCH, D.; MAWER, S.L.; SPAIN, G.E; WARD, L.; ROWE, B. Two outbreaks of Salmonella enteritidis phage type 4 infection associated with the consumption of fresh shell eggs products. Epidemiol. Infect, 103:47-52, 1989.

8. EDWARDS, P.R. \& EWING, W.H. The Genus Salmonella in "Identification of Enterobacteriaceae". 4th ed. New York, Elsevier Science Publ. Co., 1986, p. 183-340.

9. EIGLER, T.; CAFFER, M.I.; FRONCHKOWSKY, G.B. Importancia de la Salmonella enteritidis en brotes de enfermedades transmitidas por alimentos en Argentina, años 1986-1988. Rev. Arg. Microbtol., 22:41-6, 1990.

10. HEDBERG, C.W.; DAVD, M.J.; WHITE, K.E.; MacDONALD, K.L.; OSTHERHOLM, M.T. Role of egg consumption in sporadic Salmonella enteritidis and Salmonella typbimurium infections in Minnesota. J. Infect. Dis., 167: 107-11, 1993.

11. HUMPHREY, T.J.; BASKERVILLE, A.; MAWER, S.; ROWE, B.; HOPPER, S. Salmonella enteritidis phage 4 from the contents of intact eggs: a study involving naturally infected hens. Epidemiol. Infect., 103: 415-23, 1989.

12. KATALOULI, M.; SEUFFER, R.H.; WOLLIN, R.; KUHN, I.; MOLLBY, R. Variations in biochemical phenotypes and phage types of Salmonella enteritidis in Germany, 1980-92. Epidemiol. Infect., 111: 199-207, 1993.
13. LANDGRAFF, M.; GONÇALVES, J.A.; FALCÀO, D.P. Surto de toxi-infecção alimentar por Salmonella bredeney. Rev. Saúde Pública, 19: 92-3, 1985.

14. MORRIS JR., J.G.; DWYER, D.M.; HOGE, C.W.; STUBBS, A.D.; TILGHMAN, D.; GROVES, C. ISRAEL, E.; LIBONATI, J.P. Changing clonal patterns of Salmonella enteritidis in maryland: Evaluation of strains isolated between 1985 and 1990. J. Clin. Microbiol., 30: 1301-3, 1992.

15. MOTA, C.C.S.; VIEIRA, H.R.A.; PUZYNA, I.P.; KALACHE, J.; KONOLSAISEN, J.F.; CAMARGO, N.J. Toxi-infecçào alimentar pot Salmonella enteritidis. Relato de um surto ocorrido em Curitiba-PR, Brasil/julho de 1981. Hig. Alim., 2: 123-31, 1983.

16. PESSOA, G.V.A. \& SILVA, E.A.M. Milieu pour la identification presomptive rapide des enterobactéries, des aeromonas et des vibrions. Ann. Microbiol, 125A: 341-7, 1974.

17. PESSOA, G.V.A.; IRINO, K.; CALZADA, C.T; MELLES, C.E.A.; KANO, E. Ocorrência de bactérias enteropatogênicas em Sào Paulo, no septênio 1970-1976. I - Sorotipos de Salmonella isolados e identicados. Rev. Inst. Adolfo Lutz, 38:87-205, 1978.

18. POPOFF, M.Y. \& Le MINOR, L. Formules antigéntques des sérovars de Salmonella. Géme rev. Paris, Centre Collaborateur OMS de Réference et de Recherche pour les Salmonella. Institut Pasteur, Paris, França, 1992.

19. RODRIGUE, D.C.; TAUXE, R.V.; ROWE, B. International increase in Salmonella enteritids: a new pandemic? Epidemiol. Infect., 105: $21-7,1990$

20. ST. LOUIS, M.E; MORSE, D.L.; POTTER, M.E; DeMELFI, T.M.; GUZEWICH, J.J; TAUXE, R.V.; BLAKE, P.A. The Salmonella enteritidis Work Group: the emergence of grade A eggs as a major source of Salmonella enteritidis infections. JAMA, 259(14):2103-7, 1988.

21. STANLEY, J; BURNENS, A.P.; THREFALL, E.J.; CHOWDRY, N.; GOLDSWORTHY, M. Genetic relationship among strains of a national epidemic in Swizerland. Epidemiol. Infect. 108:213-20, 1992.

22. STEVENS, A; JOSEPH, C.; BRUCE, J,; FENTON, D; O'MAHONY, M; CLNNINGHAM, D.; O'CONNOR, B.; ROWE, B. A large outbreak of Salmonella enteritidis phage type 4 associated with eggs from overseas. Epidemiol. Infect., 103; 425-33, 1989.

23. VAN DE GIESSEN, A.W.; DUFRENNE, J.B.; RITMEESTER, W.S.; BERKERS, P.A.T.A.; VAN LEEWEN, W.J.; NOTERMANS, S.H.W. The identification of Salmonella enteritidis infected poultry flocks associated with an outbreak of human salmonellosis. Epidemiol. Infect., 109:405-11, 1992.

24. VUGIA, D.J.; MISHU, B.; SMITH, M.; TAVRIS D.R.; HICKMAN-BRENNER, F,W,; TAUXE, R.V. Salmonella enteritidis ourbreak in a restaurant chain: the continuing challenges of 
prevention. Epidemiol. Infect., 110: 45-61, 1993.

25. WORLD HEALTH ORGANIZATION. Guidelines on prevention and control of salmonellosis. Geneva, A.H. Linton, 1983.

\begin{abstract}
A foodbome outbreak which affected 211 persons occurred, in a School, in 1993 . The epidemiological data obtained by interviewing the affected and non affected persons sampled showed as predominant symptoms: diarthoea, fever (77.7\%), abdominal cramps (67.7\%), vomiting (65.8\%), hot-and-cold sensations $(54.5 \%)$ and headache $(44.5 \%)$. The median incubation period was of 17 hours, the limits being 3 and 29 hours. The disease period was of from 3 to 4 days. The food concerned was a kind of pate, a mayonnaise mixture prepared with fresh eggs with boiled potatoes that was consumed with bread. The biological material analysis - 3 coprocultures, and leftovers of the food revealed the presence of one and the same organism: Salmonella Enteritidis. In the food, the numbers of this bacterium per gram were sufficient to account for the menifestation of the disease $(104$ and $105 / \mathrm{g})$. The antibiogram of all the isolates showed the same sensibility pattern. The preparation related to this outbreak suggests the endogenous contamination of the eggs; the cross contamination - the outbreak affected three school periods, as the food was prepared separately for each school period; and the conditions under which the food was kept during the time from preparation to consumption. The observation of the 3 food handlers, by successive coprocultures, for one week, indicates that they were not asymptomatic carriers nor were they affected as a result of this outbreak by the causal bacteria.
\end{abstract}

Salmonella food poisoning, epidemiology. Disease outbreak. Salmonella, isolation. 